\title{
Commentary Bone versus breast density
} Jack Cuzick

Cancer Research UK Centre for Epidemiology, Mathematics and Statistics, Wolfson Institute of Preventive Medicine, Barts and the London, Queen Mary's School of Medicine and Dentistry, London, UK

Corresponding author: Jack Cuzick, Jack.cuzick@cancer.org.uk

Published: 2 May 2006

This article is online at http://breast-cancer-research.com/content/8/3/104

(c) 2006 BioMed Central Ltd

Breast Cancer Research 2006, 8:104 (doi:10.1186/bcr1407)

See related research by Crandall et al. in issue 7.6 [http://breast-cancer-research.com/content/7/6/R922] and related letter by Dite et al. in issue 8.1 [http://breast-cancer-research.com/content/8/1/401]

\section{Abstract}

The common link with oestrogen levels suggests that bone mineral density and mammographic density might also be linked. One study found weak support for this, but another study failed to provide confirmation. Overall, the relationship is very weak, if it exists at all. Other factors such as weight-bearing exercise, which have opposing impacts on these variables, may have a more dominant effect.

Dite and coworkers [1] contest the relationship previously reported by Crandall and colleagues [2] in this journal between bone mineral density and mammographic breast density. At issue here are the relationships between four variables, namely serum oestrodiol, mammographic breast density, bone mineral density and risk of breast cancer. Many of the relationships are well understood and quite strong, at least when compared with other known factors (Figure 1). Breast density is the most important known risk factor for breast cancer in terms of population attributable risk. It is both common and carries a high relative risk, of the order of fourfold to fivefold for more than $75 \%$ density compared with less than 10\% dense [3]. Likewise the relationship between serum oestrogen levels and bone mineral density (and fractures) is also strong, with well established links for increased bone loss at the menopause and protection from this with hormone replacement therapy. However, even for these cases the relationship is not complete in the sense that other mechanisms and agents make important contributions to outcome. Women with nondense breasts still get breast cancer, and agents with completely different mechanisms of action, such as the bisphosphonates, have a major effect on bone mineral density, and so causation is multifunctional. In fact some relationships suggest the opposite relation between breast and bone density (e.g. weight-bearing exercise has a beneficial effect on bone density and breast cancer risk). Other relationships such as the relation between serum oestrogen levels and breast cancer risk [4,5] or breast density [6] are undoubtedly real, but they are substantially weaker and clearly only explain part of the relationship. Reports of a relationship between bone density and breast cancer risk [7] require further validation.

A unifying hypothesis would be that oestrogen levels influence both bone density and breast density, and that the effect on breast cancer risk is mediated by the effect on breast density (Figure 1). Although there may be some truth to this, it is clearly simplistic and does not provide a full explanation. For example, Cuzick and coworkers [8] showed that tamoxifen had a large effect on breast density in a breast cancer prevention setting, but this was not large enough to explain fully its effect on breast cancer risk.

\section{Figure 1}

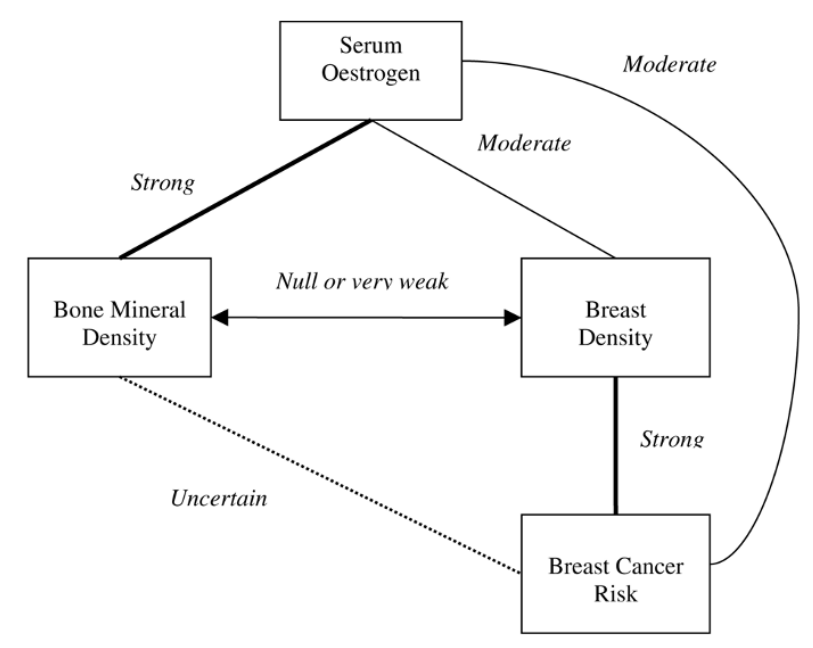

Breast density versus bone density. Inter-relation between factors associated with oestrogen levels. 
When large cohorts are evaluated, highly significant results can arise even when the correlation between two variables is modest. In these circumstances the range of possible values for the correlation of more distant measures such as breast and bone density can be very large.

The data presented in these two reports $[1,2]$ and elsewhere indicate that the relationship between breast and bone density is very weak if it is present at all, and that other nonshared factors have sufficient importance to make any common effect of oestrogen levels essentially irrelevant. In these circumstances a key objective will be to determine whether bone mineral density truly predicts breast cancer risk and, if it does, to elucidate the underlying mechanism.

\section{Competing interests}

The author declares that they have no competing interests.

\section{References}

1. Dite GS, Wark JD, Giles GG, English DR, McCredie MRE, Hopper JL: Is there a positive association between mammographic density and bone mineral density? Breast Cancer Res 2006, 8:401.

2. Crandall C, Palla S, Reboussin BA, Ursin G, Greendale GA: Positive association between mammographic breast density and bone mineral density in the Postmenopausal Estrogen/Progestin Interventions Study. Breast Cancer Res 2005, 7:R922R928.

3. Boyd NF, Byng R, Jong E: Quantitative classification of mammographic densities and breast cancer risk: results from the Canadian national breast screening study. J Natl Cancer Inst 1995, 87:670-675.

4. Kaaks R, Rinaldi S, Key TJ, Berrino F, Peeters PH, Biessy C, Dossus L, Lukanova A, Bingham S, Khaw KT, et al:: Postmenopausal serum androgens, oestrogens, and breast cancer risk. Endocr Relat Cancer 2002, 12:1071-1082.

5. Key T, Appleby P, Barnes I, Reeves G; Endogenous Hormones and Breast Cancer Collaborative Group: Endogenous sex hormones and breast cancer in postmenopausal women: reanalysis of nine prospective studies. $J$ Natl Cancer Inst 2002, 94:606-616.

6. Greendale GA, Reboussin BA, Slone S, Wasilauskas C, Pike MC, Ursin G: Postmenopausal hormone therapy and change in mammographic density. J Natl Cancer Inst 2003, 95:30-37.

7. Cauley JA, Lucas FL, Kuller LH, Vogt MT, Browner WS, Cummings SR: Bone mineral density and risk of breast cancer in older women: the study of osteoporotic fractures. Study of Osteoporotic Fractures Research Group. JAMA 1996, 276:1404-1408.

8. Cuzick J, Warwick J, Pinney E, Warren RML, Duffy SW: Tamoxifen and breast density in women at increased risk of breast cancer. J Natl Cancer Inst 2004, 96:621-628. 